\title{
On the regional climatic impact of contrails: microphysical and radiative properties of contrails and natural cirrus clouds
}

\author{
B. Strauss ${ }^{1}$, R. Meerkoetter ${ }^{1}$, B. Wissinger ${ }^{1}$, P. Wendling ${ }^{1}$, M. Hess ${ }^{2}$ \\ ${ }^{1}$ Deutsche Forschungsanstalt fuer Luft- und Raumfahrt (DLR), Institut fuer Physik der Atmosphaere, Oberpfaffenhofen, D-82234 \\ Wessling, Germany \\ ${ }^{2}$ Meteorologisches Institut der Universitaet Muenchen, Muenchen, Germany
}

Received: 17 November 1995 / Revised: 12 May 1997 / Accepted: 6 June 1997

\begin{abstract}
The impact of contrail-induced cirrus clouds on regional climate is estimated for mean atmospheric conditions of southern Germany in the months of July and October. This is done by use of a regionalized onedimensional radiative convective model (RCM). The influence of an increased ice cloud cover is studied by comparing $\mathrm{RCM}$ results representing climatological values with a modified case. In order to study the sensitivity of this effect on the radiative characteristics of the ice cloud, two types of additional ice clouds were modelled: cirrus and contrails, the latter cloud type containing a higher number of smaller and less of the larger cloud particles. Ice cloud parameters are calculated on the basis of a particle size distribution which covers the range from 2 to $2000 \mu \mathrm{m}$, taking into consideration recent measurements which show a remarkable amount of particles smaller than $20 \mu \mathrm{m}$. It turns out that a $10 \%$ increase in ice cloud cover leads to a surface temperature increase in the order of $1 \mathrm{~K}$, ranging from 1.1 to $1.2 \mathrm{~K}$ in July and from 0.8 to $0.9 \mathrm{~K}$ in October depending on the radiative characteristics of the air-traffic-induced ice clouds. Modelling the current contrail cloud cover which is near $0.5 \%$ over Europe yields a surface temperature increase in the order of $0.05 \mathrm{~K}$.
\end{abstract}

\section{Introduction}

Air traffic influences the atmosphere through the emission of various gases and particles. Among these, water vapour and aerosol particles acting as cloud nuclei are of special interest because they support cloud formation, thus modifying an important climate factor.

Correspondence to: $\mathrm{B}$. Strauss

e-mail: bernhard.strauss@der.de
Therefore, the impact of contrails, or better 'air-trafficinduced cirrus clouds' was discussed recently within the scope of air traffic and climate in general (Schumann, 1994). Liou et al. (1990) studied the global influence of contrails within a case-study, using a two-dimensional climate model. They found an increase in surface temperature of $1 \mathrm{~K}$ in the case of an increase in cloud cover by $5 \%$ between $20^{\circ}$ and $70^{\circ} \mathrm{N}$. Ponater et al. (1996) studied the influence of an increase in water vapour and in cirrus cloud cover induced by air traffic using a three-dimensional GCM. They showed that a significant climatic effect is more likely to occur on the basis of contrail cloud cover rather than on the basis of additional water vapour due to air traffic. The GCM results show an increase in surface temperature of $1 \mathrm{~K}$ at $50^{\circ} \mathrm{N}$ for a contrail cloud cover of $5 \%$.

However, one may expect contrails to have a stronger impact on a regional scale than on a global scale. To estimate this, a case-study is carried out within this paper for an area of increased air traffic in southern Germany. This is done by use of a one-dimensional radiative convective model (RCM), originally developed by Liou and $\mathrm{Ou}(1983)$ and modified to allow modelling of regional climate by taking into account advection as a third energy flux besides radiation and convection. The effects of an increased ice cloud cover on the equilibrium temperature profile of a mean July and October atmosphere were simulated.

Special emphasis is laid on the parameterization of the radiative characteristics of ice clouds. There are two types of ice cloud used in the model: cirrus and contrail. An increase in ice cloud cover is modelled twice, using both cloud types, in order to estimate the influence of the cloud radiative characteristics on the results. Corresponding RCM input parameters are the transmittance and the reflectance in the solar, and the emittance, the transmittance and the reflectance in the terrestrial spectral range. Values of these quantities are obtained by radiative transfer model (RTM) calculations. Ice clouds in the model are assumed to consist of particles in the range $2-2000 \mu \mathrm{m}$. The size distribution for particles 
smaller than $20 \mu \mathrm{m}$ is based on recent in situ measurements which are presented in Sect. 2; for particles greater than $20 \mu \mathrm{m}$ a parameterization of Heymsfield and Platt (1984) is used. Contrails are assumed to consist of a larger portion of smaller particles and less of the bigger ones compared to natural cirrus clouds. The ice water content, however, is assumed to be the same in both cloud types, for reasons of better comparability. It is anticipated that the portion of small particles has an appreciable influence on the radiative properties of ice clouds (Arnott et al., 1994). Section 3 describes the model modifications, Sect. 4 presents and discusses the resulting equilibrium temperature profiles.

\section{Measurements of microphysical properties in cirrus clouds and contrails}

In situ measurements by use of an ice replicator [built by J. Hallett, Desert Research Institute (DRI), Reno, Nevada, USA] were carried out in both natural cirrus and aged contrails. This was done within the campaign 'CIRRUS '92' organized by 'Deutsche Forschungsanstalt für Luft- und Raumfahrt' (DLR). It took place between 1 and 19 October 1992 in south Germany. On 15 October measurements were taken in a natural cirrostratus cloud located ahead of a frontal system related to a strong low over Denmark. On 9 October measurements were taken in contrails with ages in the order of half an hour embedded in arising cirrus. In this case a high was located over Central Europe, a low over the Mediterranean Sea and advection of warm air in southern Germany just started from the south. A comparison of these two measurements is of special interest with regard to a possible difference in the microphysical behaviour of these two cloud types. The question of how representative these two clouds were remains open up to now.

The principle of the ice replicator (see Fig. 1) is quite easy: the particles fly through an inlet situated at the tip of the instrument, sized $2 \times 7 \mathrm{~mm}^{2}$, and impact on a coated leader film which is transported just behind that

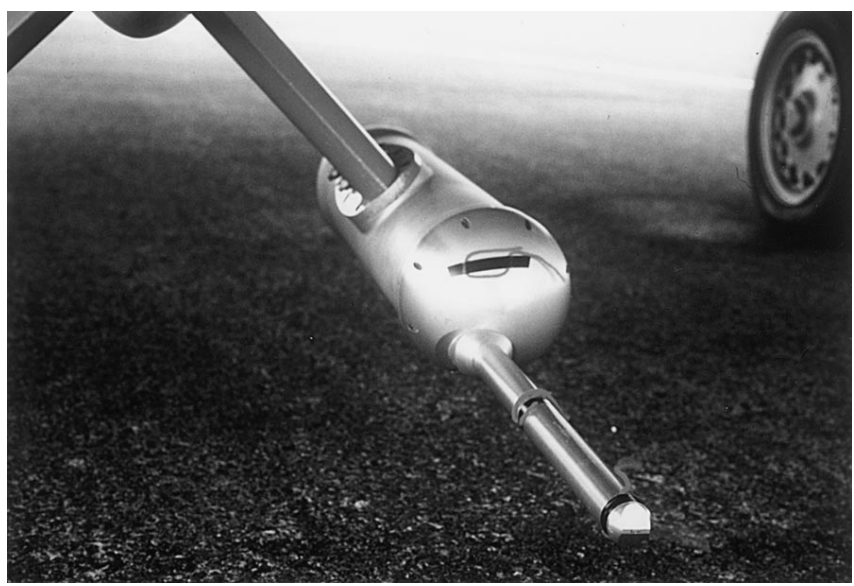

Fig. 1. Ice replicator mounted on the DLR research aircraft 'Falcon' entrance. The impacts of the particles are conserved in the coating and are analysed by microscopy, digitization of the microscope pictures and image processing software. Thus information on particle shapes, sizes, concentration and size distribution is obtained. The lower resolution of the instrument is about $4 \mu \mathrm{m}$, depending on the quality of the coating which does not always have the same characteristics. A source of uncertainty concerning absolute particle numbers is the uncertainty due to the collection efficiency for particles smaller than approximately $10 \mu \mathrm{m}$, which is not known accurately. Particles larger than approximately $100 \mu \mathrm{m}$ normally break by impaction and information on these particles is therefore weak. Regions showing fragments of broken particles were excluded from evaluation. Nevertheless, there remains an uncertainty due to misclassification of some broken material. This effect is contrary to the collection efficiency effect. Figure 2 shows eight size distributions of the cirrus cloud measured on 15 October 1992 taken from eight different parts of this cloud, thus representing a measure of the natural variability. Also shown is a parameterization for cirrus cloud particles larger than $20 \mu \mathrm{m}$ in size for temperatures of $-55^{\circ} \mathrm{C}$ and $-40^{\circ} \mathrm{C}$ (Heymsfield and Platt, 1984; Liou, 1992). The temperature in the cloud was about -55 to $-57^{\circ} \mathrm{C}$. One can see three important features:

1. there are many 'small' particles, i.e. particles smaller than about $20 \mu \mathrm{m}$ in size;

2. the measured size distributions coincide with the parameterization of Heymsfield and Platt in the overlap size regime;

3. the variability is in the order of one magnitude.

The strong fluctuations at sizes larger than about $20 \mu \mathrm{m}$ are due to the size of sampling volume, which is comperatively small for particles of this size regime. It is in the order of several thousand $\mathrm{cm}^{3}$. The collection

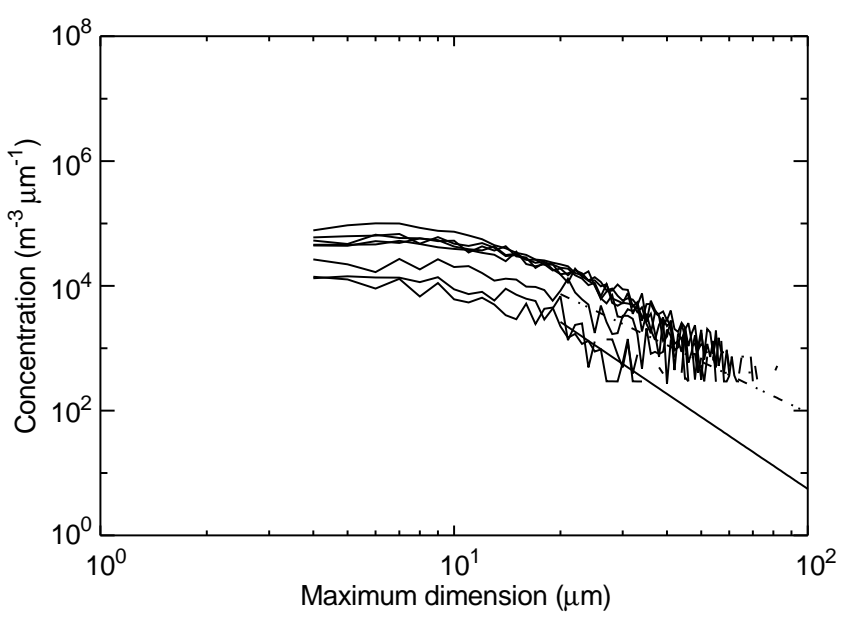

Fig. 2. Size distributions in a cirrostratus cloud measured on 15 October 1992 over southern Germany. The eight curves represent eight different parts of the cloud and thereby give a measure of the natural variability. The two lines represent parameterizations for particles larger than $20 \mu \mathrm{m}$ for $-55^{\circ} \mathrm{C}$ (solid) and $-40^{\circ} \mathrm{C}$ (dash - three dots) after Heymsfield and Platt, 1984 
efficiency is assumed to be 1 for all sizes, i.e. numbers for particles smaller than approximately $10 \mu \mathrm{m}$ are probably slightly underestimated. Integration gives a mean particle concentration of $0.7 \mathrm{~cm}^{-3}$, with values ranging from 0.5 to $1.1 \mathrm{~cm}^{-3}$.

These values can be compared to data obtained by measurements with a Counterflow Virtual Impactor (CVI) in natural cirrus clouds, as presented by Stroem (1993). The CVI detects ice particles up to $30 \mu \mathrm{m}$ by measuring the concentration of the nuclei and the ice water content of the particles. CVI values range from 0.1 to $1 \mathrm{~cm}^{-3}$ and therefore confirm the replicator data.

Figure 3 shows the corresponding results for the aged contrails on 9 October. The temperature in these contrails was between $-37^{\circ} \mathrm{C}$ and $-45^{\circ} \mathrm{C}$. The mean concentration value is found to be $1.3 \mathrm{~cm}^{-3}$, again assuming a collection efficiency of 1 , with values ranging from 0.8 to $1.6 \mathrm{~cm}^{-3}$. A comparison of the two clouds is shown in Fig. 4. The two curves represent mean values of the size distribution for the two cloud types. One can see that the particle concentration for the aged contrails

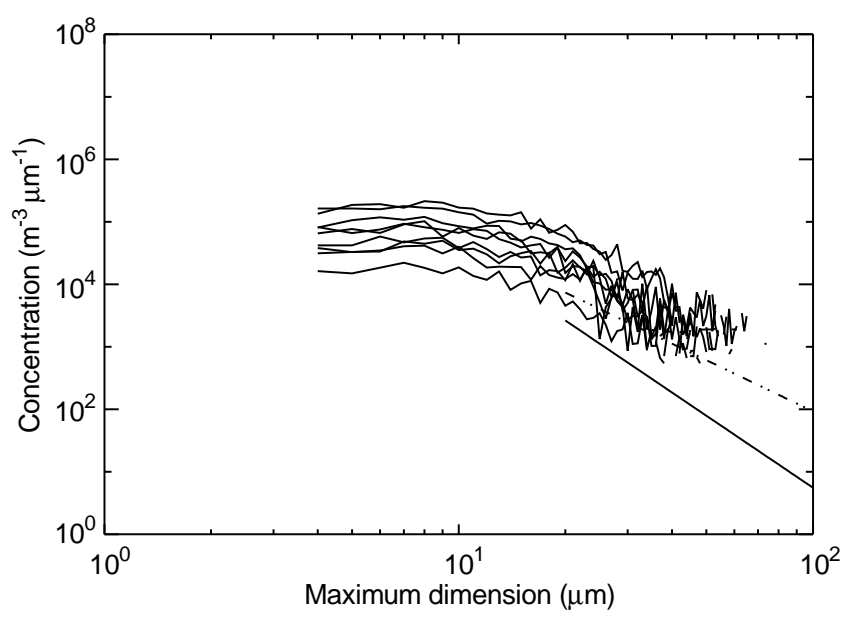

Fig. 3. Size distributions measured in aged contrails on 9 October 1992 over Southern Germany. Lines as in Fig. 2

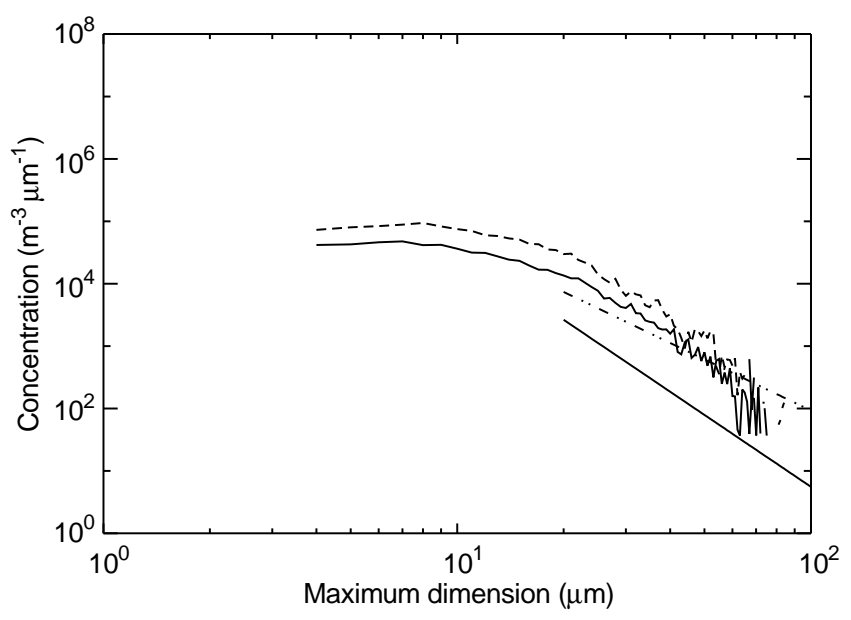

Fig. 4. Comparison of size distribution for natural cirrus (15 October 1992, solid) and aged contrails (9 October 1992, dashed). Lines as in Fig. 2 is larger for all sizes measured by the ice replicator. But the difference is significantly less than the variability of each of the two clouds.

\section{The radiative convective model and its modification}

The RCM output of the original model version represents an atmospheric state of long-term and global averaging. It divides the atmosphere into 21 layers containing three cloud layers and calculates a temperature profile representing an equilibrium state between radiation and convection within each layer. The whole spectral range comprises six spectral intervals in the solar and five intervals in the terrestrial region.

The temperature profile is computed on the basis of the Curtis matrix principle, i.e. starting with an emittance, reflectance and transmittance value and a firstguess temperature value for each atmospheric model layer and then applying a perturbation scheme. This immediately gives the equilibrium state temperature profile, i.e. no time-stepping method is used. Values in cloudy layers are assumed to be dominated by the cloud particles. Figure 5 gives an overview of the procedure. For more details see Liou and Ou (1983).

To permit simulations on a regional scale and for limited time-periods, advection has to be taken into consideration. Furthermore, the following variables have to be specified for the considered region and time: (1) solar zenith angle, (2) water vapour profile, (3) ozone profile, (4) cloud cover, (5) surface albedo, (6) Bowen ratio. All of these values except the cloud cover are assumed to be constant in the frame of this study. Cloud cover values for mid-level and low clouds are fixed, whereas high cloud cover is varied. More details are given in Appendix B.

Special emphasis is given to the parameterization of the optical properties of ice clouds. In the model's original version, ice clouds consist of cylindrically shaped monodisperse ice particles with a mean length of $200 \mu \mathrm{m}$, a mean radius of $30 \mu \mathrm{m}$ and a mean concentration of $0.05 \mathrm{~cm}^{-3}$.

However, recent research results force these assumptions to be modified. It turned out that models tend to underestimate the solar ice cloud albedo when compared to measurements (Stackhouse and Stephens, 1991). As a consequence, two hypotheses are made to explain this discrepancy: in today's models, particles are usually described as spheres or hexagons. Hypothesis (1) says that particle shapes have to be modelled more precisely with respect to multibranched particles which are regularly found in ice clouds and which could cause increased backscattering as compared to simple hexagonally shaped columns and plates (Wielicki et al., 1990). Hypothesis (2) concerns the particle size. Little is known about particles smaller than $50 \mu \mathrm{m}$ due to the lower resolution of instruments usually employed for in situ measurements of ice particles. Ice cloud models usually assume particles with a minimum size of $20 \mu \mathrm{m}$ or even larger. Hypothesis (2) says that a significant amount of smaller particles have an appreciable influence on the 


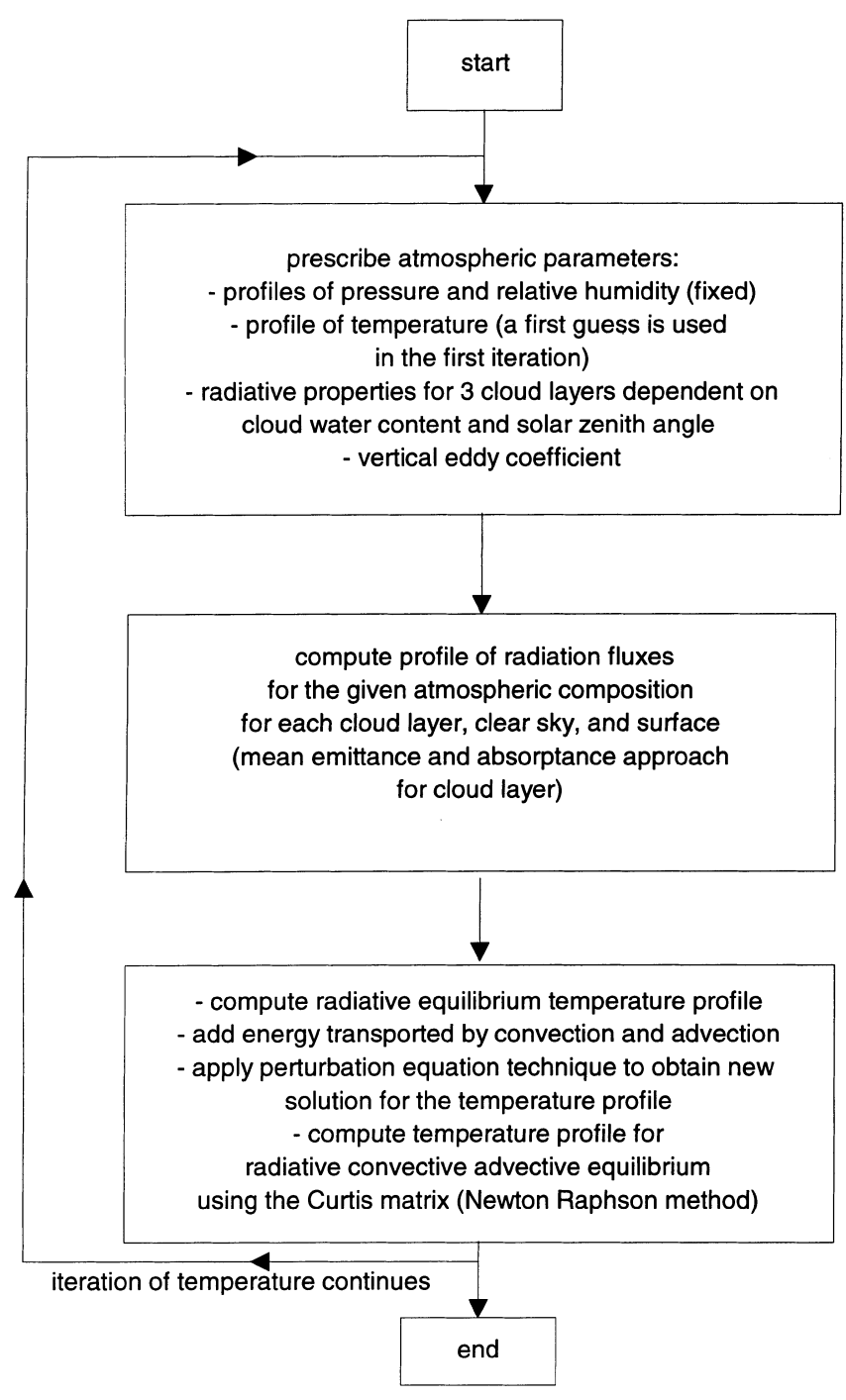

Fig. 5. Flow diagram showing the principle procedure of the RCM. Each iteration repeats the calculations of the vertical exchange coefficient and of the profile of the radiative fluxes on the basis of the new temperature profile. Advection is taken into consideration as a third energy flux besides radiation and convection in the modified version of the RCM which is used in this study

radiative characteristics of ice clouds by enlarging the number of backscattered photons and herewith increasing cloud albedo. Model calculations (Macke, 1993; Iaquinta et al., 1995; Strauss, 1996) make hypothesis (1) appear unlikely, whereas recent in situ measurements as presented in the previous section support hypothesis (2). Therefore, the ice cloud parameterization used in the RCM was modified by assuming hexagonally shaped ice particles in the solar spectral range, and cirrus particle size distributions in the small-particle regime as based on our measurements (see Sect. 2) and those of Heymsfield and Platt (1984). In the terrestrial spectral range, Mie-calculations were carried out for volume equivalent spheres.

The following two subsections describe the parameterization of the optical properties of ice clouds and of the advection in detail.

\subsection{Calculation of the radiative properties of ice clouds}

3.1.1 Procedure. Radiative properties of ice clouds in the RCM are described by the broadband transmittance and reflectance in the solar spectral range and in addition the emittance in the terrestrial spectral range. These quantities were calculated with a separate radiation transfer model (RTM) based on the Matrix Operator Method (Plass et al., 1973) by the following steps:

1. Calculation of the phase function $\phi$ (solar region), asymmetry factor $g$ (terrestrial region), volume extinction coefficient $\sigma$, and single scattering albedo $\omega$ on the basis of the particle-size distribution and the spectral complex refractive index of ice (Warren, 1984). In the solar region these parameters are derived for hexagonally shaped particles under the assumption of geometrical optics (Hess and Wiegner, 1994). In the terrestrial spectral range Mie-calculations have been performed for volume equivalent spheres.

2. Calculation of spectral downward- and upwarddirected radiative fluxes at cloud top and base with an RTM. The ice cloud layer is embedded between 9.6 and $11.0 \mathrm{~km}$.

3. Calculation of broadband transmittance, reflectance and emittance by use of wavelength integrated fluxes at cloud top and base within the solar and terrestrial spectral range.

3.1.2 Microphysical properties of cirrus and contrails. Size distributions are specified for two cloud types: cirrus and contrails. Table 1 gives the discretized cirrus size distribution as derived from two separate data sources. $A$ and $B$ designate the half-width and the length of the representative hexagonal ice particles. For cirrus cloud particles smaller than $20 \mu \mathrm{m}$ the size distribution is based on in situ measurements as presented in Sect. 2. For cirrus cloud particles larger than $20 \mu \mathrm{m}$ the size distribution is based on a parameterization of Heymsfield and Platt (1984) (using a revised version in Liou, 1992), which is a function of temperature. For reasons of consistency, the range $-55^{\circ} \mathrm{C}$ to $-60^{\circ} \mathrm{C}$ is used here, because temperature values within this range were measured during the flight in the cloud on 15 October 1992. Taking the particle numbers of Heymsfield and Platt (1984), Liou (1992) directly, however, leads to a significant smaller ice water content than that measured by these two papers which is $2.077 \cdot 10^{-3} \mathrm{gm}^{-3}$. We assume that this discrepancy is due to the assumption that particles in our model have hexagonal shapes in all size classes, whereas the measurements show aggregates in the range of larger particles. For a certain diameter, an aggregate contains a significantly larger volume than a column. In order to adjust the ice water content value in the model to the measured value, particle numbers in size classes V to VIII were increased by a factor of 3.47.

For consistency of the following comparison the ice water content within contrails is assumed to be the same 
Table 1. Modelled size distribution of cirrus cloud particles. The particle concentration is $0.58 \mathrm{~cm}^{-3}$, the ice water content 2.077 . $10^{-3} \mathrm{gm}^{-3}$

\begin{tabular}{lcccl}
\hline Size class & $\begin{array}{l}\text { Represented } \\
\text { size range } \mu \mathrm{m}\end{array}$ & $A \mu \mathrm{m}$ & $B \mu \mathrm{m}$ & $\begin{array}{l}\text { Particle } \\
\text { number } \mathrm{m}^{-3}\end{array}$ \\
\hline I & $2-6$ & 1.4 & 3.5 & $1.69 \cdot 10^{5}$ \\
II & $6-20$ & 4 & 10 & $3.87 \cdot 10^{5}$ \\
III & $20-40$ & 10 & 30 & $1.77 \cdot 10^{4}$ \\
IV & $40-90$ & 22 & 60 & $3.19 \cdot 10^{3}$ \\
V & $90-200$ & 41 & 130 & $1.40 \cdot 10^{3}$ \\
VI & $200-400$ & 60 & 300 & $1.75 \cdot 10^{2}$ \\
VII & $400-900$ & 80 & 600 & $3.16 \cdot 10^{1}$ \\
VIII & $900-2000$ & 110 & 1300 & $3.99 \cdot 10^{0}$ \\
\hline
\end{tabular}

Table 2. Modelled size distribution of contrail particles. The particle concentration is $1.0 \mathrm{~cm}^{-3}$, the ice water content $2.077 \cdot 10^{-3} \mathrm{gm}^{-3}$

\begin{tabular}{lcccl}
\hline Size class & $\begin{array}{l}\text { Represented } \\
\text { size range } \\
\mu \mathrm{m}\end{array}$ & $A \mu \mathrm{m}$ & $B \mu \mathrm{m}$ & $\begin{array}{l}\text { Particle number } \\
\mathrm{m}^{-3}\end{array}$ \\
\hline I & $2-6$ & 1.4 & 3.5 & $2.91 \cdot 10^{5}$ \\
II & $6-20$ & 4 & 10 & $6.67 \cdot 10^{5}$ \\
III & $20-40$ & 10 & 30 & $3.05 \cdot 10^{4}$ \\
IV & $40-90$ & 22 & 60 & $5.51 \cdot 10^{3}$ \\
V & $90-200$ & 41 & 130 & $2.42 \cdot 10^{3}$ \\
VI & $200-400$ & 60 & 300 & 0 \\
VII & $400-900$ & 80 & 600 & 0 \\
VIII & $900-2000$ & 110 & 1300 & 0 \\
\hline
\end{tabular}

as that for the natural cirrus case. Having no precise information on particle number densities for sizes larger than $20 \mu \mathrm{m}$, we assume that the relative particle size distribution is the same as that for the natural cirrus case (Table 1), though with an upper size limit of $200 \mu \mathrm{m}$. This gives also qualitative agreement with the measurements of Gayet et al. (1996). As a result of the adjustment of the ice water content there are more small particles in contrails than in natural cirrus, which is consistent with our measurements.

\subsubsection{Radiative properties of contrails and natural cirrus} clouds. The radiative transfer model adopted to calculate vertical profiles of upward- and downward-directed fluxes is based on the matrix operator theory (Plass et al., 1973). This RTM accounts for processes of multiple scattering, absorption and thermal emission. The cloud optical properties are described by $\phi$ (solar), $g$ (terrestrial), $\sigma$ and $\omega$. Besides the cloud parameters, the RTM needs the corresponding optical parameters for aerosol particles. Furthermore, the vertical profiles of temperature, pressure and air density, as well as the absorber masses of the relevant gases, characterize the atmospheric state. These meteorological parameters are given for our model atmospheres in Appendix B. Table 6 in Appendix A shows the spectral resolution within the solar spectral range as used in the RTM.

In the solar region, the sharp forward peak of the cirrus phase function is truncated by applying the delta-

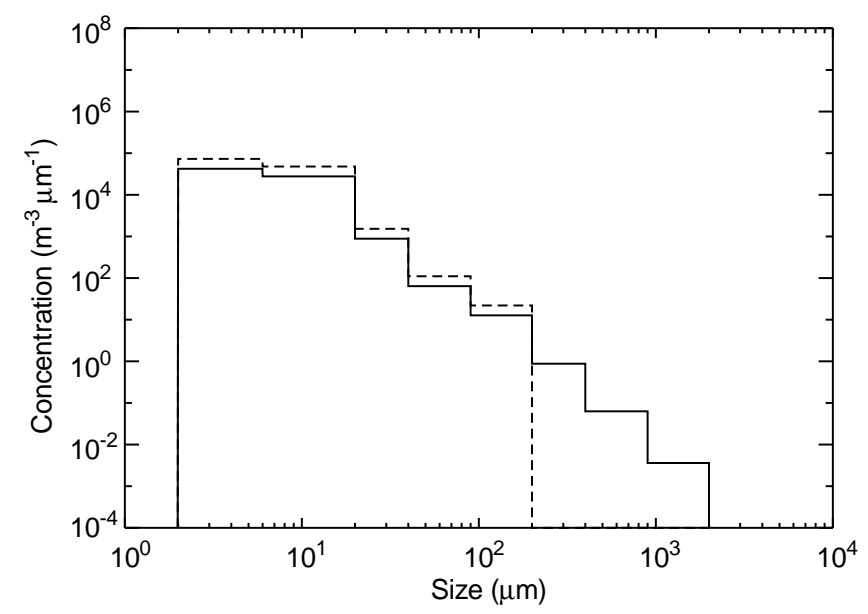

Fig. 6. Modelled size distributions (steps) for natural cirrus (solid) and contrails (dashed)

function approximation. In the terrestrial range, a Henyey-Greenstein approximation of the phase function is adopted which depends only on the asymmetry factor. The transmission functions of the relevant gases valid in the spectral subintervals are approximated by exponential sum fitting.

Table 7 in Appendix A gives the values of $C, g$ and $\omega$ for the cirrus and contrail cloud as calculated for hexagonally shaped particles with geometrical optics. $C$ designates the extinction cross-section and equals the extinction coefficient normalized to one particle per $\mathrm{cm}^{-3}$. Note that the $g$ values are shown in the table but are subsequently not used. For the model calculations, the complete phase function is used. Note that the spectral resolution is not identical to that in the RTM (see Table 6) however, it accounts for a proper representation of the radiative properties which in turn mainly follow the spectral behaviour of the complex refractive index of ice. Phase functions are calculated at wavelengths $0.550,1.100,1.400,1.905,2.600$ and $3.077 \mu \mathrm{m}$. These wavelengths are chosen as representative with respect to the spectral behaviour of the refractive index of ice.

To obtain the analogous values for the RTM input spectral intervals (Table 6), a proper mean value is calculated by

$\overline{x_{j}}=\frac{\sum_{i} x_{i} E_{i} \Delta \lambda_{i, j}}{\sum_{i} E_{i} \Delta \lambda_{i, j}}$,

where $x$ represents the variables $\sigma$ and $\omega, \overline{x_{j}}$ designates the mean value of the $j$ th spectral interval $\sum_{i} \Delta \lambda_{i, j}$ within the solar spectral range. The variable $E_{i}$ is the solar constant at the wavelength $i$.

The first column in Table 8 in Appendix A shows the spectral resolution in the terrestrial region used by the RTM. In order to obtain $\sigma, g$ and $\omega$ values in the terrestrial region, Mie-calculations for corresponding spherical particles were carried out within each spectral interval at its central wavelength given in Table 8, where the conversion from hexagonal particles into corresponding spheres is done by calculation of equivalent 
volume. It is expected that such spheres give better $\omega$ values compared to spheres of equal surface (Takano and Liou, 1989).

Downward- and upward-directed solar fluxes at cloud top and base result from RTM calculations for the isolated cloud layer as radiative transfer medium. In a next step, the cloud transmittance is derived by relating the downward directed fluxes at cloud top and base, respectively. The ratio of upward and downward flux at cloud top correspondingly gives the cloud reflectance. Solar zenith angles are cosine weighted means over the solar day for July and October in Munich. Results are shown in Table 3.

As expected, transmittances increase and reflectances decrease with decreasing particle concentration. The extinction coefficient value is found to be 0.130 and $0.198 \mathrm{~km}^{-1}$ for cirrus and contrails, respectively, at a wavelength of $0.55 \mu \mathrm{m}$. Values of the cloud optical thickness at a wavelength of $0.55 \mu \mathrm{m}$ are 0.18 and 0.28 for cirrus and contrails, respectively.

To obtain emittance, transmittance and reflectance in the terrestrial spectral range, RTM calculations were carried out for two different vertical atmospheric segments: (1) the atmosphere between surface and cloud top and (2) the cloud layer only. The first serves to obtain the upward fluxes at cloud top $f_{\text {top }} \uparrow$ and cloud base $f_{\text {base }} \uparrow$, the latter gives the fluxes emitted by the cloud layer itself, designated as $f c l_{\text {top }} \uparrow$ and $f c l_{\text {base }} \downarrow$. The upward-directed emittance is calculated according to $f_{c l} l_{\text {top }} \uparrow / \varsigma T_{\text {top }}^{4}$, where $\varsigma$ denotes the Stefan-Boltzmann constant and $T_{\text {top }}$ the temperature at cloud top. The downward-directed emittance is calculated analogously. In the RCM the mean of these two emittance values is used. The transmittance is given by $\left(f_{\text {top }} \uparrow-f c l_{\text {top }} \uparrow\right) /$ $f_{\text {base }} \uparrow$, the reflectance by $\left(f_{\text {base }} \downarrow-f_{c} l_{\text {base }} \downarrow\right) / f_{\text {base }} \uparrow$. Table 4 lists the results, Table 5 presents the derived values for cloud emittance, transmittance and reflectance.

Table 3. Solar radiative properties of cirrus and contrails as derived from RTM calculations. (Jci: July, cirrus, Jco: July, contrails, Oci: October, cirrus, Oco: October, contrails)

\begin{tabular}{llll}
\hline Case & Solar zenith angle & Transmittance & Reflectance \\
\hline Jci & $58.71^{\circ}$ & 0.932 & 0.057 \\
Jco & $58.71^{\circ}$ & 0.908 & 0.080 \\
Oci & $69.78^{\circ}$ & 0.891 & 0.095 \\
Oco & $69.78^{\circ}$ & 0.855 & 0.131 \\
\hline
\end{tabular}

Table 4. Radiative fluxes in the terrestrial spectral range; $f_{\text {top }} \uparrow:$ upward flux at cloud top, $f_{\text {base }} \uparrow$ : upward flux at cloud base, $f_{\text {base }} \downarrow$ : downward flux at cloud base, $f_{c} l_{\text {top }} \uparrow$ : upward flux at cloud top (cloud only), $f c_{\text {base }} \downarrow$ : downward flux at cloud base (cloud only), other designations as in Table 3

\begin{tabular}{llllll}
\hline Case & $\begin{array}{l}f_{\text {top }} \uparrow \\
\mathrm{Wm}^{-2}\end{array}$ & $\begin{array}{l}f_{\text {base }} \uparrow \\
\mathrm{Wm}^{-2}\end{array}$ & $\begin{array}{l}f_{\text {base }} \downarrow \\
\mathrm{Wm}^{-2}\end{array}$ & $\begin{array}{l}f_{c l} l_{\text {top }} \uparrow \\
\mathrm{Wm}^{-2}\end{array}$ & $\begin{array}{l}f_{c l_{\text {base }} \downarrow} \\
\mathrm{Wm}^{-2}\end{array}$ \\
\hline Jci & 245.1 & 286.7 & 75.5 & 57.0 & 59.9 \\
Jco & 231.8 & 286.7 & 86.3 & 62.2 & 65.3 \\
Oci & 238.5 & 272.3 & 54.4 & 43.4 & 45.5 \\
Oco & 227.8 & 272.3 & 62.9 & 48.7 & 51.0 \\
\hline
\end{tabular}

Table 5. Derived ice cloud radiative properties in the terrestrial spectral range

\begin{tabular}{llll}
\hline Case & Emittance & Transmittance & Reflectance \\
\hline Jci & 0.386 & 0.656 & 0.054 \\
Jco & 0.421 & 0.592 & 0.073 \\
Oci & 0.320 & 0.716 & 0.033 \\
Oco & 0.359 & 0.658 & 0.044 \\
\hline
\end{tabular}

As expected, emittances and reflectances increase with increasing particle concentration, whereas transmittances decrease with increasing particle concentrations.

\subsection{Parameterization of advection}

3.2.1 Method. In our case-study an atmospheric segment with vertical boundaries along the region of southern Germany is modelled. For simplicity it is called in the following 'atmospheric box'. In contrast to modelling on a global scale, net fluxes of energy through the lateral boundaries of this atmospheric box have to be taken into account. It is assumed that the net energy flux which leaves the top of the box as radiation (in the considered time-period) equals the energy flux which is gained through the lateral faces as advection. The profile of advected energy is set proportional to the wind profile. The value of the energy flux leaving the atmospheric box at the top is taken from ERBE (Earth Radiation Budget Experiment) satellite data. This flux is -59 and $97 \mathrm{Wm}^{-2}$ in the months of July and October, respectively, the minus sign in the July case representing an energy gain for the box. More details concerning the satellite data are given in Appendix B. Values for the vertical profile of the wind speed are taken from radiosonde data, 'Munich' station, averaged for the years 1981-1985.

Within the frame of this study, no feedback mechanisms concerning advection are taken into consideration.

3.2.2 Results of regionalization. Figure 7 shows RCM results for the reference case, i.e. the case with climatological values of cirrus cloud cover in July. Two temperature profiles are shown: one results from including advection as already outlined, whereas the other results from neglecting it. For comparison, the climatological July values as derived from radiosonde data are shown.

Calculated temperatures fit quite well throughout the whole troposphere. A small inversion layer is modelled at the surface but not seen in the climatology values. This indicates that the Bowen ratio might not be representative for this case, however, in this study only temperature differences are of interest.

Figure 8 shows corresponding temperature profiles for October conditions. Noteworthy is the great influence of advection inducing a temperature difference of approximately $25 \mathrm{~K}$ throughout the troposphere. It is 


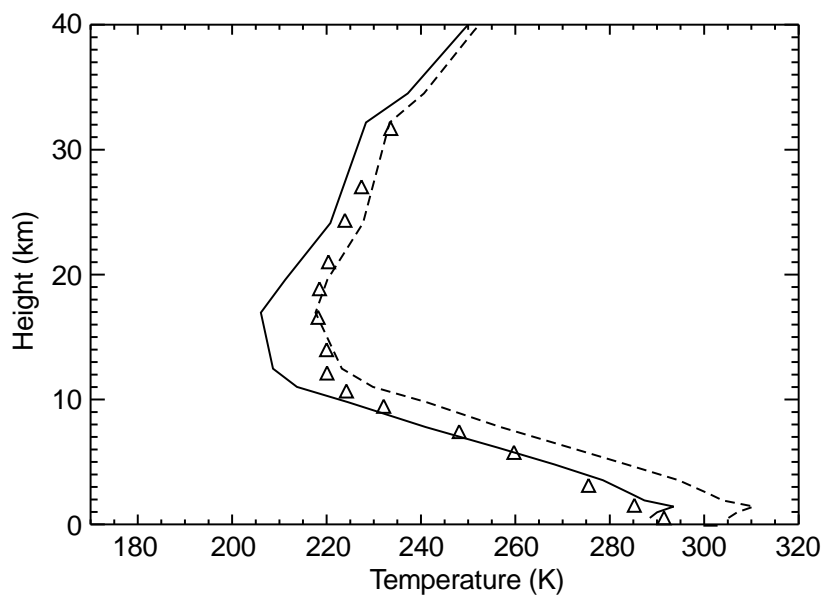

Fig. 7. Modelled temperature profiles for July with (solid) and without (dashed) advection compared to radiosonde measurements (triangles)

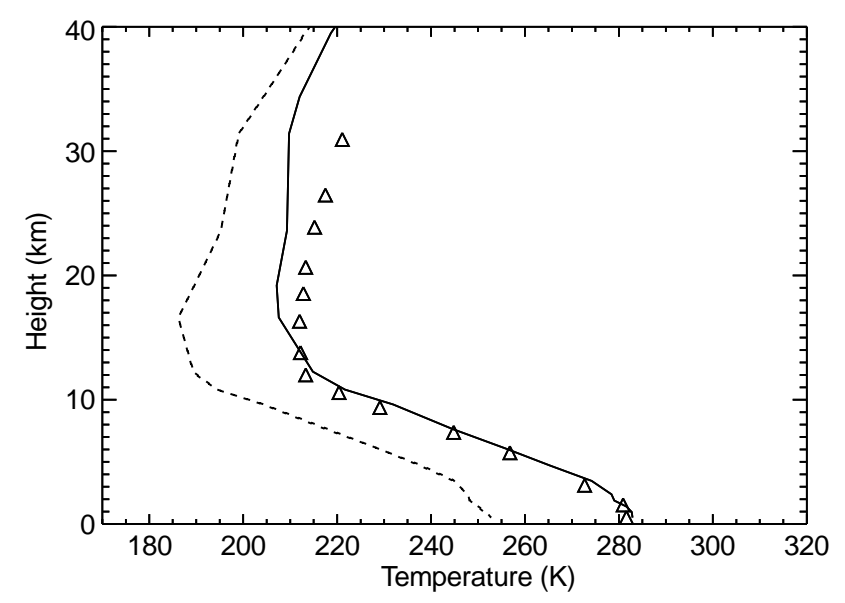

Fig. 8. As in Fig. 1., but for October conditions

important to note that the uncertainty of the satellite data is in the order of $10 \mathrm{Wm}^{-2}$, which corresponds to an uncertainty in the temperature profile in the order of only $3 \mathrm{~K}$.

\section{Results and discussion}

The impact of ice clouds induced by air traffic is estimated by comparing the RCM results for an increased high cloud cover with those for the reference cases in July and October. It is assumed that the ice cloud cover increases at the expense of the uncovered area.

The surface temperature results are shown in Fig. 9. An ice cloud cover increase due to contrails by $10 \%$ causes surface temperature increases of 1.1 and $0.8 \mathrm{~K}$ in July and October, respectively. Assuming that the increased cloud cover is due to clouds which have natural cirrus properties, these values are 1.2 and $0.9 \mathrm{~K}$, respectively. Thus, for both months the increase in high cloud cover due to natural cirrus warms the surface more than the increase due to contrails. Obviously, the

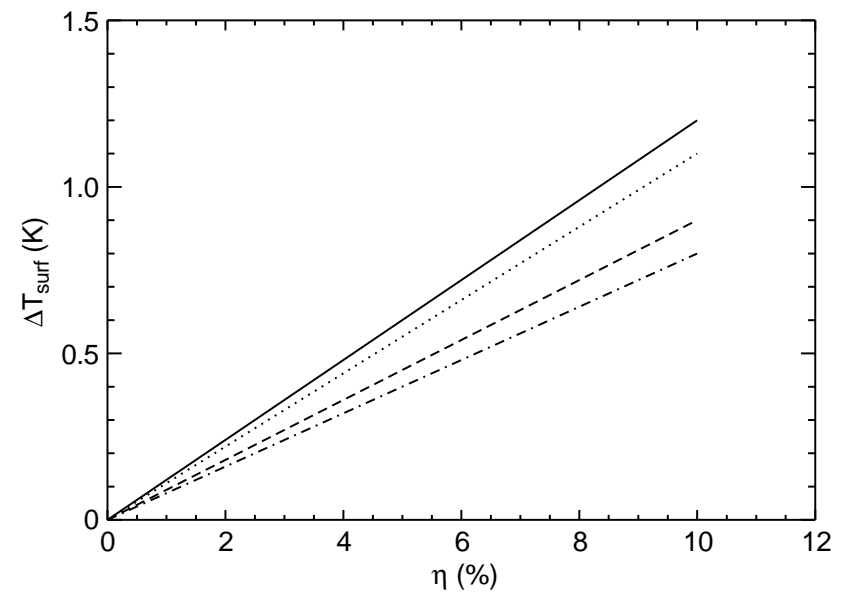

Fig. 9. Increase in surface temperature $\Delta T_{\text {surf }}$ in dependence on additional ice cloud cover $\eta$ due to contrails and cirrus in the case of mean July and October conditions over southern Germany. Solid: July, cirrus; dotted: July, contrails; dashed: October, cirrus; dashdotted: October, contrails

primarily larger shortwave albedo of the contrails due to more smaller particles leads to less warming than in the case of natural cirrus, even if the emittance of contrails is larger than that of natural cirrus. Figure 9 shows a linear relation between cloud cover and surface temperature, because the RCM weights flux linearly with cloud cover. Part of the contrails certainly will occur over midand low-level clouds. Since the RCM does not consider overlapping effects of several cloud layers, our values for surface warming represent an upper limit.

As a further result the radiative forcing at the top of the atmosphere with a fixed temperature and humidity profile is obtained. In the July case the upward terrestrial flux at the top of the atmosphere is reduced by $3.3 \mathrm{Wm}^{-2}$ in the case of a $10 \%$ increase in cirrus cloud cover. The corresponding decrease in the solar flux is $0.5 \mathrm{Wm}^{-2}$. In the October case, the terrestrial flux is reduced by $2.6 \mathrm{Wm}^{-2}$, and the solar flux by $0.1 \mathrm{Wm}^{-2}$. The values in the contrail cases are slightly lower.

The current cloud cover which is due to contrails and thereby obviously due to air traffic is estimated to be in the order of $0.5 \%$ over Europe (Bakan et al., 1994). This increase in cloud cover might be regarded as the minimum amount of air traffic induced cloud cover. Therefore it is expected that the increases in surface temperature are approximately 0.06 and $0.05 \mathrm{~K}$ in July and October, respectively.

With regard to the uncertainty in our results, we varied the advection term by $10 \mathrm{Wm}^{-2}$ (that corresponds to an uncertainty of $10 \mathrm{Wm}^{-2}$ in the satellite radiation measurement), the resulting uncertainty in the surface temperature is about $0.02 \mathrm{~K}$ (change from 96.75 to $106.75 \mathrm{Wm}^{-2}$ in the satellite measured net radiative flux for the October case). Assuming a doubling of the latent heat flux at surface (which is much more than a realistic assumption), the resulting uncertainty in the surface temperature is about $0.01 \mathrm{~K}$ (in the October case). These values show that these uncertainties have no important influence on the results. 
In comparison to a corresponding global sensitivity study for the climatic effect of an additional contrail cloudiness in the North Atlantic region (Ponater et al., 1996), our value for the increase in the surface temperature in July is of the same order of magnitude. However, in this GCM calculation, the ocean temperature was fixed, and so the true response of additional cloudiness is slightly underestimated.

The question of the climatic importance is relative: compared to an increase in the temperature of $1 \mathrm{~K}$ between the Middle Ages and today, our $0.05 \mathrm{~K}$ value is surely not significant. On the other hand, climate change is a composite of multiple effects, and one should keep air traffic in mind as being one of these. Furthermore, our results represent equilibrium conditions, and the question of possible effects in the non-equilibrium state remains open, e.g. influences in the day-to-night differences in temperature.

The results give an idea of how sensitive the regional temperature profile reacts on changes in the ice cloud layer which are due to changes in cloud cover, radiative properties of the ice clouds and solar zenith angle. However, we must keep in mind that our results are based on the assumption that the radiation balance on top of the atmosphere is fixed to the value that belongs to the undisturbed case, and further that large-scale advection of energy into the area does not change. In view of the small temperature changes induced by the changes in cirrus cloud cover, these assumptions are expected to be fulfilled to a first order, and our results represent an upper limit of the regional effects of an additional cloudiness caused by air traffic. This is also supported by the results from a three-dimensional GCM which include feedback mechanisms and show the same order of magnitude (Ponater et al., 1996).

Acknowledgements. For friendly help concerning the albedo values and discussions on aerosol distributions we thank W. Thomas. Concerning ERBE data our thanks are given to M. Rieland and K. Standfuss (Meteorologisches Institut der Universitaet Hamburg). Last but not least we are very grateful to K. N. Liou and S. C. Ou for having made available to us a version of their radiative convective model. This work was supported by the Bavarian regional climate research programme (BayFORKLIM), which was funded by the 'Bayerisches Ministerium fuer Landesentwicklung und Umweltfragen'. Their financial support is greatly acknowledged.

Topical Editor L. Eymard thanks P. Hignett and S. Kinne for their help in evaluating this paper.

\section{Appendix A}

\section{Tables indicating RTM calculations}

These tables, referred to in the text are put in an Appendix for reasons of clarity and readability.

Table 6. Spectral resolution in the solar spectral range

\begin{tabular}{ll}
\hline Interval number & $\begin{array}{l}\text { Wavelength range } \\
\mu \mathrm{m}\end{array}$ \\
\hline 1 & $0.20-0.30$ \\
2 & $0.30-0.35$ \\
3 & $0.35-0.40$ \\
4 & $0.40-0.45$ \\
5 & $0.45-0.50$ \\
6 & $0.50-0.55$ \\
7 & $0.55-0.60$ \\
8 & $0.60-0.80$ \\
9 & $0.80-0.90$ \\
10 & $0.90-1.00$ \\
11 & $1.00-1.20$ \\
12 & $1.20-1.60$ \\
13 & $1.60-2.20$ \\
14 & $2.20-3.00$ \\
15 & $3.00-3.40$ \\
\hline
\end{tabular}

Table 7. Optical parameters of cirrus and contrail used in the solar region. Symbols without a hat denote cirrus parameters, symbols with a hat denote contrail parameters

\begin{tabular}{lllllll}
\hline$\lambda$ & $C$ & $\hat{C}$ & $g$ & $\hat{g}$ & $\omega$ & $\hat{\omega}$ \\
$\mu \mathrm{m}$ & $\mathrm{m}^{-1} \mathrm{~cm}^{3}$ & $\mathrm{~m}^{-1} \mathrm{~cm}^{3}$ & & & & \\
\hline 0.423 & $2.25 \cdot 10^{-4}$ & $1.99 \cdot 10^{-4}$ & 0.752 & 0.746 & 1.000 & 1.000 \\
0.550 & $2.25 \cdot 10^{-4}$ & $1.99 \cdot 10^{-4}$ & 0.757 & 0.751 & 1.000 & 1.000 \\
0.635 & $2.25 \cdot 10^{-4}$ & $1.99 \cdot 10^{-4}$ & 0.760 & 0.753 & 1.000 & 1.000 \\
0.780 & $2.26 \cdot 10^{-4}$ & $1.99 \cdot 10^{-4}$ & 0.762 & 0.755 & 1.000 & 1.000 \\
0.830 & $2.26 \cdot 10^{-4}$ & $1.99 \cdot 10^{-4}$ & 0.762 & 0.754 & 1.000 & 1.000 \\
0.015 & $2.26 \cdot 10^{-4}$ & $1.99 \cdot 10^{-4}$ & 0.764 & 0.756 & 0.999 & 1.000 \\
1.100 & $2.26 \cdot 10^{-4}$ & $1.99 \cdot 10^{-4}$ & 0.766 & 0.759 & 0.999 & 1.000 \\
1.200 & $2.26 \cdot 10^{-4}$ & $1.99 \cdot 10^{-4}$ & 0.768 & 0.761 & 0.998 & 0.999 \\
1.400 & $2.26 \cdot 10^{-4}$ & $2.00 \cdot 10^{-4}$ & 0.771 & 0.764 & 0.995 & 0.997 \\
1.449 & $2.29 \cdot 10^{-4}$ & $2.02 \cdot 10^{-4}$ & 0.789 & 0.778 & 0.943 & 0.959 \\
1.504 & $2.32 \cdot 10^{-4}$ & $2.03 \cdot 10^{-4}$ & 0.804 & 0.792 & 0.900 & 0.924 \\
1.615 & $2.30 \cdot 10^{-4}$ & $2.02 \cdot 10^{-4}$ & 0.791 & 0.779 & 0.939 & 0.956 \\
1.850 & $2.27 \cdot 10^{-4}$ & $2.00 \cdot 10^{-4}$ & 0.785 & 0.777 & 0.985 & 0.990 \\
1.905 & $2.31 \cdot 10^{-4}$ & $2.03 \cdot 10^{-4}$ & 0.803 & 0.793 & 0.930 & 0.950 \\
2.000 & $2.37 \cdot 10^{-4}$ & $2.07 \cdot 10^{-4}$ & 0.831 & 0.819 & 0.844 & 0.874 \\
2.190 & $2.30 \cdot 10^{-4}$ & $2.02 \cdot 10^{-4}$ & 0.807 & 0.798 & 0.959 & 0.972 \\
2.600 & $2.35 \cdot 10^{-4}$ & $2.06 \cdot 10^{-4}$ & 0.867 & 0.859 & 0.910 & 0.933 \\
3.077 & $2.59 \cdot 10^{-4}$ & $2.28 \cdot 10^{-4}$ & 0.941 & 0.938 & 0.534 & 0.534 \\
3.413 & $2.52 \cdot 10^{-4}$ & $2.21 \cdot 10^{-4}$ & 0.878 & 0.869 & 0.606 & 0.614 \\
\hline
\end{tabular}


Table 8. Optical parameters of cirrus and contrail cloud models in the terrestrial region. Symbols without a hat denote cirrus parameters, symbols with a hat denote contrail parameters

\begin{tabular}{lllllll}
\hline$\lambda$ & $\sigma$ & $\hat{\sigma}$ & $g$ & $\hat{g}$ & $\omega$ & $\hat{\omega}$ \\
$\mu \mathrm{m}$ & $\mathrm{km}^{-1}$ & $\mathrm{~km}^{-1}$ & & & & \\
\hline 4.08 & 0.1623 & 0.2553 & 0.830 & 0.820 & 0.748 & 0.769 \\
4.26 & 0.1728 & 0.2715 & 0.852 & 0.844 & 0.727 & 0.746 \\
4.40 & 0.1696 & 0.2669 & 0.875 & 0.868 & 0.693 & 0.709 \\
4.49 & 0.1783 & 0.2813 & 0.880 & 0.874 & 0.676 & 0.690 \\
4.65 & 0.1732 & 0.2722 & 0.874 & 0.867 & 0.701 & 0.718 \\
4.88 & 0.1938 & 0.3082 & 0.863 & 0.857 & 0.783 & 0.804 \\
5.13 & 0.1895 & 0.3010 & 0.871 & 0.866 & 0.791 & 0.813 \\
5.41 & 0.1951 & 0.3091 & 0.886 & 0.881 & 0.764 & 0.785 \\
5.71 & 0.1748 & 0.2768 & 0.909 & 0.905 & 0.684 & 0.698 \\
6.06 & 0.1727 & 0.2742 & 0.918 & 0.914 & 0.608 & 0.615 \\
6.45 & 0.1742 & 0.2763 & 0.904 & 0.899 & 0.638 & 0.648 \\
6.90 & 0.1639 & 0.2574 & 0.904 & 0.898 & 0.634 & 0.645 \\
7.41 & 0.1670 & 0.2618 & 0.896 & 0.889 & 0.649 & 0.661 \\
8.00 & 0.1628 & 0.2557 & 0.891 & 0.884 & 0.669 & 0.683 \\
8.70 & 0.1485 & 0.2300 & 0.897 & 0.890 & 0.671 & 0.688 \\
9.30 & 0.1429 & 0.2197 & 0.902 & 0.894 & 0.639 & 0.654 \\
9.76 & 0.1266 & 0.2927 & 0.913 & 0.905 & 0.612 & 0.625 \\
10.53 & 0.1048 & 0.2541 & 0.947 & 0.938 & 0.426 & 0.412 \\
11.76 & 0.1399 & 0.2138 & 0.883 & 0.871 & 0.441 & 0.429 \\
12.90 & 0.1597 & 0.2496 & 0.846 & 0.835 & 0.468 & 0.460 \\
13.79 & 0.1570 & 0.2429 & 0.841 & 0.829 & 0.500 & 0.495 \\
14.81 & 0.1845 & 0.2889 & 0.804 & 0.790 & 0.547 & 0.548 \\
16.00 & 0.1686 & 0.2627 & 0.798 & 0.783 & 0.580 & 0.586 \\
18.18 & 0.1449 & 0.2188 & 0.768 & 0.747 & 0.629 & 0.644 \\
22.22 & 0.1193 & 0.1747 & 0.752 & 0.729 & 0.732 & 0.763 \\
28.57 & 0.0902 & 0.1232 & 0.793 & 0.763 & 0.605 & 0.631 \\
40.00 & 0.0829 & 0.1148 & 0.847 & 0.811 & 0.350 & 0.314 \\
66.67 & 0.1107 & 0.1511 & 0.684 & 0.621 & 0.406 & 0.380 \\
\hline & & & & & &
\end{tabular}

\section{Appendix B}

Input parameters for the radiative convective model and the matrix operator model

This appendix summarizes the input parameters describing atmospheric conditions for the RCM as well as for the matrix operator model in the cases of both months studied, July and October.

Tables 9 and 10 list the input parameters concerning the atmospheric conditions in the case of July and October, respec-

Table 9. Radiosonde values over southern Germany in the month of July, averages from 1981 to 1985

\begin{tabular}{lcccc}
\hline $\begin{array}{l}\text { Height } \\
\mathrm{km}\end{array}$ & $\begin{array}{l}\text { Pressure } \\
\mathrm{hPa}\end{array}$ & $\begin{array}{l}\text { Temperature } \\
\mathrm{K}\end{array}$ & $\begin{array}{l}\text { Air density } \\
\mathrm{g} \mathrm{cm}\end{array}$ & $\begin{array}{l}\text { Humidity } \\
\%\end{array}$ \\
\hline 31.85 & 10 & 233.6 & 14.91 & \\
27.13 & 20 & 227.4 & 30.64 & \\
24.43 & 30 & 223.9 & 46.68 & \\
21.09 & 50 & 220.4 & 79.03 & \\
18.91 & 70 & 218.5 & 111.6 & \\
16.62 & 100 & 218.1 & 159.7 & 19.5 \\
14.01 & 150 & 220.0 & 237.5 & 20.6 \\
12.15 & 200 & 220.1 & 316.5 & 40.3 \\
10.70 & 250 & 224.2 & 388.4 & 44.5 \\
9.47 & 300 & 232.5 & 449.5 & 44.4 \\
7.44 & 400 & 248.1 & 561.5 & 42.9 \\
5.78 & 500 & 259.7 & 670.2 & 44.2 \\
3.13 & 700 & 275.5 & 883.1 & 58.5 \\
1.54 & 850 & 285.2 & 1033.8 & 67.6 \\
\hline
\end{tabular}

Table 10. Radiosonde values over southern Germany in the month of October, averages from 1981 to 1985

\begin{tabular}{lclcl}
\hline $\begin{array}{l}\text { Height } \\
\mathrm{km}\end{array}$ & $\begin{array}{l}\text { Pressure } \\
\mathrm{hPa}\end{array}$ & $\begin{array}{l}\text { Temperature } \\
\mathrm{K}\end{array}$ & $\begin{array}{l}\text { Air density } \\
\mathrm{g} \mathrm{cm}^{-3}\end{array}$ & $\begin{array}{l}\text { Humidity } \\
\%\end{array}$ \\
\hline 31.01 & 10 & 222.5 & 15.66 & \\
26.50 & 20 & 218.2 & 31.93 & \\
23.91 & 30 & 216.0 & 48.38 & \\
20.67 & 50 & 214.3 & 81.28 & \\
18.55 & 70 & 213.9 & 114.0 & \\
16.30 & 100 & 213.4 & 163.2 & 18.9 \\
13.75 & 150 & 213.8 & 244.4 & 20.8 \\
11.94 & 200 & 215.2 & 323.8 & 33.2 \\
10.52 & 250 & 220.8 & 394.4 & 35.2 \\
9.31 & 300 & 228.7 & 457.0 & 37.6 \\
7.32 & 400 & 243.9 & 571.3 & 34.1 \\
5.68 & 500 & 255.7 & 681.2 & 35.7 \\
3.08 & 700 & 271.2 & 899.2 & 46.3 \\
1.51 & 850 & 279.5 & 1059.0 & 56.1 \\
\hline
\end{tabular}

tively, from radiosonde data. Temperatures are used as starting point for the RCM calculations and data for modelling the optical properties of the cirrus cloud layer. The data are taken from radiosonde measurements averaged over the years 1981 to 1985 , DWD (Deutscher Wetterdienst) station Munich, except the humidity values in 100 and $150 \mathrm{hPa}$, which are averages from 1987 to 1989 due to lack of corresponding values in the mentioned time-period.

Humidity values above $100 \mathrm{hPa}$ as well as all other values above $10 \mathrm{hPa}$ are taken from McClatchey et al. (1972), mid-latitude summer atmosphere, 1962 and US standard atmosphere for July and October, respectively. Surface values are 1981 to 1985 averages from the 'Europaeischer Wetterbericht' (Deutscher Wetterdienst), and ozone data are from DWD station Hohenpeissenberg (also 1981 to 1985$)$.

\section{Cloud cover and liquid water path}

Cloud cover values are taken from Warren et al. (1988). Values are based on ground observation averages between 1971 and 1981. Spatial resolution of these data is $5^{\circ} \times 5^{\circ}$, temporal resolution is 3 months. The following classification is used: $\mathrm{Cu}, \mathrm{Cb}, \mathrm{St}, \mathrm{Ns}, \mathrm{As}, \mathrm{Ac}$ and $\mathrm{Ci}$. To get cloud cover values for the three cloud layers in the $\mathrm{RCM}, \mathrm{Cu}, \mathrm{Cb}$, St, Ns are chosen to give the low cloud cover, $\mathrm{Cb}$, Ns, As, Ac to give the mid-level cloud cover and Ci to give the high cloud cover, following a procedure used by Liou in the original version of the RCM (Liou et al., 1985). This leads to cloud cover values $0.31,0.21,0.07$ and 0.41 for low, middle, high clouds and clear sky, respectively in the month of July. The corresponding values for October are $0.56,0.34,0.16$ and 0.59 , respectively.

The RCM is unable to calculate interactions between clouds. Therefore, the radiative flux computations are performed for different atmospheres containing one cloud layer each for low, middle and high clouds and one clear atmosphere are calculated separately and radiation fluxes are weighted afterwards with the corresponding cloud-cover values. For this reason, the cloud-cover values given are compacted in the RCM. This is done by multiplication with a constant factor (less than 1) in the way that the sum of the cloud cover and the clear sky fraction add up to 1 . Note, however, that the interaction between a single cloud layer and the surface is taken into consideration.

The liquid water path value of low clouds is taken from Liou and $\mathrm{Ou}(1983)$ as $60.411 \mathrm{gm}^{-2}$, for mid-level clouds to $54.06 \mathrm{gm}^{-2}$ in the present study. The ice water path for cirrus cloud is assumed to be $2.908 \mathrm{~g} \mathrm{~m}^{-2}$ according to measurements of Heymsfield and Platt (1984). 


\section{Surface albedo}

The surface solar albedo values are taken from Koepke et al. (1992). These values are based on satellite measurements. In the case of October, values from 10:00, 13:00 and 16:00 local time are available, corresponding to sun elevations of $26.87^{\circ}, 31.06^{\circ}$ and $12.29^{\circ}$, respectively. Interpolation to $20.22^{\circ}$ elevation angle which is used in the RCM leads to an albedo of $11.3 \%$. This value is used for the October calculations.

In the case of July, only the 13:00 local time value was available. This value is $15.6 \%$. Due to the fact that the albedo has a minimum value at the time of the highest sun elevation angles, an albedo value slightly higher than this value was chosen as representative in the July calculations. The value was estimated to be $17 \%$ (W. Thomas, personal communication).

\section{Aerosol data}

Aerosol data are chosen to represent continental conditions for both months studied, July and October (M. Hess and P. Koepke, personal communication). Table 11 shows the assumed aerosol components and particle numbers. These values are valid for sea level. The dependence on altitude is modelled after

$$
n(h)=n(0) \exp (-h / Z),
$$

where $n$ denotes the particle number, $h$ the altitude and $Z$ a reference altitude which is $8 \mathrm{~km}$. For more details, including refractive indices, see Deepak and Gerber (1983).

\section{Satellite data used for parameterization of advection}

Satellite data are taken from ERBE (Earth Radiation Budget Experiment) via the 'Meteorologisches Institut der Universitaet Hamburg'. Spatial resolution of these data is $2.5^{\circ} \times 2.5^{\circ}$. The data are taken from $47.5^{\circ}$ to $50.0^{\circ} \mathrm{N}$ and $10.0^{\circ}$ to $12.5^{\circ} \mathrm{E}$ and cover quite accurately the area of Bavaria, southern Germany. In the case of July, a 5-year average of monthly averaged net fluxes (top of atmosphere) is used (1985-1989). Values are 68.75, 55.96, 54.63, 61.94 and $51.80 \mathrm{Wm}^{-2}$ for the 5 months, respectively. The mean value used is $58.62 \mathrm{Wm}^{-2}$. For October, corresponding data from 2 years 1985 and 1986 are used. Values are -99.00 and $-94.50 \mathrm{Wm}^{-2}$, respectively, and the mean value $-96.75 \mathrm{Wm}^{-2}$ is used.

Table 11. Aerosol conditions used for calculations

\begin{tabular}{llll}
\hline $\begin{array}{l}\text { Height } \\
\mathrm{km}\end{array}$ & Aerosol type & $\begin{array}{l}\text { Number } \\
\mathrm{cm}^{-3}\end{array}$ & $\begin{array}{l}\text { Mode radius } \\
\mu \mathrm{m}\end{array}$ \\
\hline-2 & water soluble $(70 \%)$ & 7000 & 0.0285 \\
& insoluble & 0.4 & 0.471 \\
& soot & 8300 & 0.0118 \\
$2-12$ & water soluble $(50 \%)$ & 438 & 0.0262 \\
& insoluble & $1.24 \cdot 10^{-3}$ & 0.471 \\
& soot & 292 & 0.0118 \\
\hline
\end{tabular}

Table 12. Bowen ratios for July and October, southern Germany used in the calculations

\begin{tabular}{ll}
\hline Month & Sensible heat/latent heat \\
& $\mathrm{Wm}^{-2} / \mathrm{Wm}^{-2}$ \\
\hline July & $24 / 130$ \\
October & $9 / 31$ \\
\hline
\end{tabular}

\section{Bowen ratio data}

The relationship between surface fluxes of sensible and latent heat strongly dominates the temperature profile near surface. Values were taken from Berz (1996). These values were measured in 1964 on the area of a meteorological research station of the University of Munich, Germany, located in the surroundings of the city. It is not clear how representative these values are for whole southern Germany and how representative they are for a monthly mean averaged over many years. However, due to lack of better data these values, given in Table 12, are used in the calculations.

\section{References}

Arnott, W. P., Y. Y. Dong, J. Hallett, and M. R. Poellot, Role of small ice crystals in radiative properties of cirrus: a case-study, FIRE II, November 22, 1991, J. Geophys. Res., 99, 1371-1381, 1994.

Bakan, S., M. Betancor, V. Gayler, and H. Grassl, Contrail frequency over Europe from NOAA-satellite images, Ann. Geophysicae, 12, 962-968, 1994.

Berz, G., Energiehaushalt der Bodenoberflaeche, Meteorologisches Institut der Universitaet Muenchen, 1969.

Deepak, A., and H. E. Gerber (eds.), Report of the expert meeting on aerosols and their climatic effects, WCP-55, 1983.

Europaeischer Wetterbericht, DWD, Amtsblatt des Deutschen Wetterdienstes, D6168, ISSN 0341-2970, 1981-1985.

Gayet, J. -F., G. Febvre, G. Brogniez, H. Chepfer, W. Renger, and P. Wendling, Microphysical and optical properties of cirrus and contrails: cloud field study on 13 October 1989, J. Atmos. Sci., 53, 126-138, 1996.

Hess, M., and M. Wiegner, COP: data library of optical properties of hexagonal ice crystals, Appl. Optt., 33, 7740-7746, 1994.

Heymsfield, A. J., and C. M. R. Platt, A parameterization of the particle size spectrum of ice clouds in terms of the ambient temperature and the ice water content, J. Atmos. Sci., 41, 846855,1984

Iaquinta, J., H. Isaka, and P. Personne, Scattering phase function of bullet rosette ice crystals, J. Atmos. Sci., 52, 1401-1413, 1995.

Koepke, P., R. Meerkoetter, W. Thomas, and B. Vogel, Albedo in Mitteleuropa aus METEOSAT-Minimumcounts, Meteorologisches Institut der Universitaet Muenchen, Forschungsbericht 'MIM-FB92-S4', 1992.

Liou, K. N. Radiation and cloud processes in the atmosphere, Oxford University Press, Oxford, 1992.

Liou, K. N., and S. C. Ou, Theory of equilibrium temperatures in radiative-turbulent atmospheres, J. Atmos. Sci., 40, 214-229, 1983.

Liou, K. N., S. C. Ou, and P. J. Lu, Interactive cloud formation and climatic temperature perturbations, J. Atmos. Sci., 42, 1969-1981, 1985.

Liou, K. N., S. C. Ou, and G. Koenig, An investigation on the climatic effect of contrail cirrus, in Air traffic and the environment - background, tendencies and potential global atmospheric effects', Ed. U. Schumann, Proc DLR Int Coll, Bonn, Germany, Springer, Berlin Heidelberg New York 1990.

McClatchey, R. A., R. W. Fenn, J. E. A. Selby, F. E. Volz, and J. S. Garing, Optical properties of the atmosphere (third edition), Air Force Systems Command, United States Air Force, AFCRL-720497, 1972.

Macke, A., Scattering of light by polyhedral ice crystals, Appl. Opt., 32, 2780-2788, 1993.

Plass, G. N., G. W. Kattawar, and F. E. Catchings, Matrix operator theory of radiative transfer. 1: Rayleigh scattering, Appl. Opt., 12, 314-329, 1973.

Ponater, M., S. Brinkop, R. Sausen, and U. Schumann, Simulating the global atmospheric response to aircraft water vapour emissions and contrails: a first approach using a GCM, Ann. Geophysicae, 14, 941-960, 1996. 
Schumann, U., On the effect of emissions from aircraft engines on the state of the atmosphere, Ann. Geophysicae, 12, 365-384, 1994.

Stackhouse, P. W., and G. L. Stephens, A theoretical and observational study of the radiative properties of cirrus: results from FIRE 1986, J. Atmos. Sci., 48, 2044-2059, 1991.

Strauss, B., On the scattering behaviour of bullet-rosette and bullet-shaped ice crystals, Ann. Geophysicae, 14, 566-573, 1996.

Stroem, J., Numerical and airborne experimental studies of aerosol and cloud properties in the troposphere, Dissertation, Dept. of Meteorology, Stockholm University, ISBN 91-7153-168-8, 1993.

Takano, Y., and K. -N. Liou, Solar radiative transfer in cirrus clouds. Part I: single-scattering and optical properties of hexagonal ice crystals, J. Atmos. Sci., 46, 3-19, 1989.
Warren, S. G., Optical constants of ice from the ultraviolet to the microwave, Appl. Opt., 23, 1206-1223, 1984.

Warren, S. G., C. J. Hahn, J. London, R. M. Chervin, and R. L. Jenne, Global distribution of total cloud cover and cloud type amounts over land, NCAR, Technical Notes, 1988.

Wielicki, B. A., J. T. Suttles, A. J. Heymsfield, R. M. Welch, J. D. Spinhirne, M. C. Wu, D. O'C. Starr, L. Parker, and R. F. Arduini, The 27-28 October 1986 FIRE IFO cirrus study: comparison of radiative transfer theory with observations by satellite and aircraft, Mon. Weather Rev., 118, 2356-2376, 1990. 